\title{
A rare case of gastric pneumatosis in a seven-month-old infant - case report
}

\author{
Anna Socha, Anna Socha-Banasiak, Krzysztof Pacześ, Ryszard Makosiej, Elżbieta Czkwianianc \\ Department of Gastroenterology, Allergology and Pediatrics, Polish Mother's Memorial Hospital Research Institute, Lodz, Poland
}

\section{ABSTRACT}

Pneumatosis is a rare condition characterised by the presence of gas collections within the wall of the alimentary tract occurring both in paediatric and adult patients. In this manuscript, we present a seven-month-old boy admitted to our department due to episodes of emesis and prolonged diarrhoea. Initial X-ray of the abdomen revealed a significantly dilated stomach with gas collections within its wall. The boy was diagnosed with stomach wall pneumatosis resulting from paralytic ileus caused by prolonged gastric infection. After immediate nasogastric decompression, implementation of broad-spectrum antibiotics, and temporary total parenteral nutrition complete resolution of gastric pneumatosis and clinical improvement were achieved.

\section{KEY WORDS:}

stomach, infant, pneumatosis, paralytic ileus.

\section{INTRODUCTION}

Pneumatosis is a radiological finding characterised by the presence of gas collections within the wall of the alimentary tract that may affect any part of the gastrointestinal tract from the oesophagus to the rectum. The causes responsible for this condition can vary from benign to life-threatening. Therefore, it is important to take into consideration multiple factors and whole patient data to determine the best treatment approach.

\section{CASE REPORT}

A seven-month-old boy with Down syndrome and medical history of congenital duodenal obstruction with surgical correction at the age of one month presented to the hospital with repetitive postprandial vomiting for a day and a three-week history of diarrhoea.
On the admission to our department the child's vital signs were stable. On physical examination abdominal distention and typical Down syndrome features (i.e. large protruding tongue, flattened nose, upward slanting eyelids, single transverse palmar crease) were notable. Otherwise, his physical examination was unremarkable. Initial blood investigations showed no significant abnormalities: red blood cells $(\mathrm{RBC}) 5.75 \times 10^{6} / \mu \mathrm{l}$ (reference range 4.2 $5.75 \times 10^{6} / \mu \mathrm{l}$ ); haemoglobin $(\mathrm{HbC}) 15.3 \mathrm{~g} / \mathrm{dl}$ (reference range $11-15 \mathrm{~g} / \mathrm{dl}$ ); white blood cells $(\mathrm{WBC}) 7.98 \times 10^{3} / \mu \mathrm{l}$ (reference range $\left.5-17.5 \times 10^{3} / \mu \mathrm{l}\right)$; C-reactive protein (CRP) $0.5 \mathrm{mg} / \mathrm{dl}$ (reference range $<1.0 \mathrm{mg} / \mathrm{dl}$ ); glucose 103 (reference range 60-99 mg/dl); Na 135 mmol/l (reference range $133-142 \mathrm{mmol} / \mathrm{l}$ ); $\mathrm{K} 4.8 \mathrm{mmol} / \mathrm{l}$ (reference range 3.5-6.1 mmol/l); Cl $107 \mathrm{mmol} / \mathrm{l}$ (reference range $96-108 \mathrm{mmol} / \mathrm{l}$ ); creatinine $0.33 \mathrm{mg} / \mathrm{dl}$ (reference range $0.2-0.4 \mathrm{mg} / \mathrm{dl}$ ); ALT $46.00 \mathrm{IU} / \mathrm{l}$ (reference range 15-48 IU/l); AST $44.00 \mathrm{IU} / \mathrm{l}$ (reference range 25-55 IU/l);

\section{ADDRESS FOR CORRESPONDENCE:}

Anna Socha, Department of Gastroenterology, Allergology and Pediatrics, Polish Mother's Memorial Hospital Research Institute, 281/289 Rzgowska St., 93-338 Lodz, Poland, ORCID: 0000-0001-7170-6500, e-mail: annasocha29@gmail.com 
amylase $87.00 \mathrm{IU} / \mathrm{l}$ (reference range 30-100 IU/l); lipase $37.00 \mathrm{IU} / 1$ (reference range 13-95 IU/1). Stool tests for rotavirus and adenovirus antigen were negative.

During first day of hospitalisation postprandial vomiting continued, and the child did not pass any stools and stopped passing gas. On repeated abdomen physical examination bowel sounds in all quadrants were decreased.

Abdominal ultrasonography revealed a significantly dilated stomach and duodenum, filled with fluids. An abdominal X-ray confirmed stomach dilatation and showed the presence of gastric intramural gas, without any sign of free intraperitoneal or portal venous air (Fig. 1).

The patient was placed on bowel rest. Nasogastric decompression was employed. During the procedure, $160 \mathrm{ml}$ of brown gastric juice was retrieved. Blood, stool, and gastric fluid specimens were obtained for culture testing.

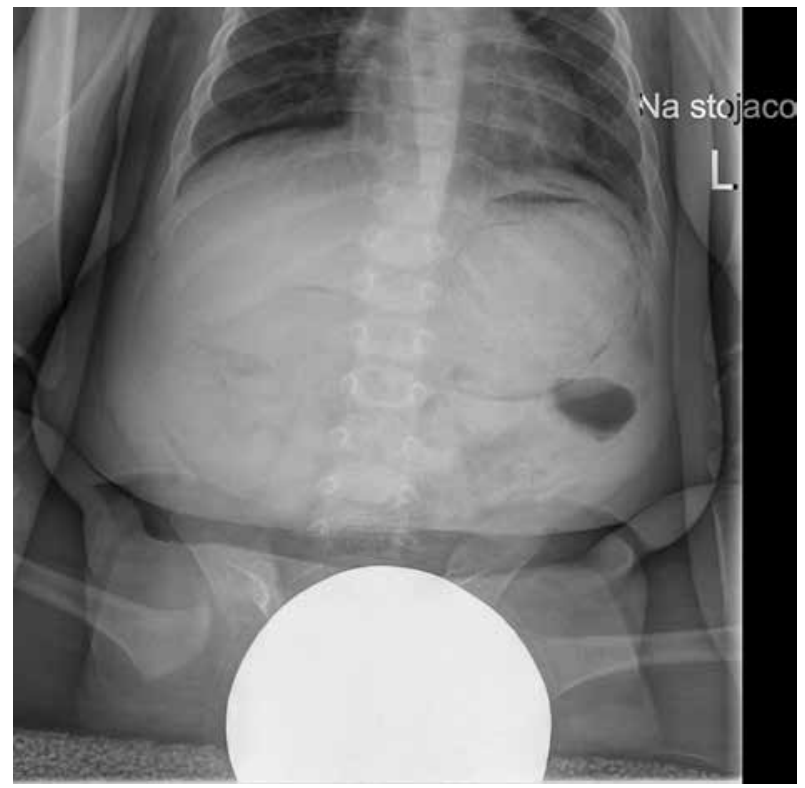

FIGURE 1. Abdominal X-ray - stomach dilatation and gastric pneumatosis

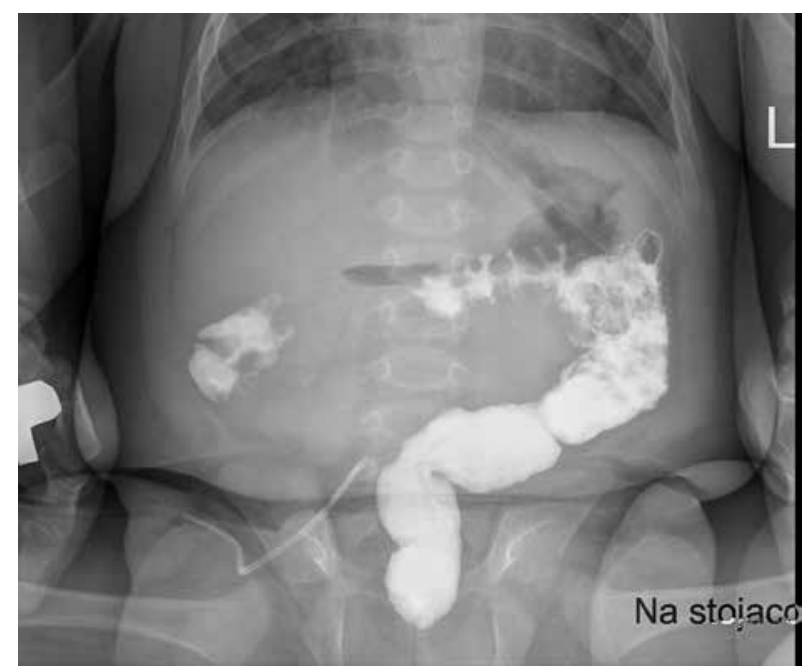

FIGURE 2. Follow-up abdominal X-ray after two days - no sign of gastric pneumatosis
An upper gastrointestinal contrast study with iodinated contrast agent, performed after decompression of the stomach, showed free passage through the stomach and duodenum. During a surgical consultation, no indications for surgical intervention were found. The patient was diagnosed with paralytic ileus caused by prolonged gastrointestinal tract infection, which, with accompanying vomiting and increased stomach pressure, led to stomach wall pneumatosis.

The patient was treated with broad-spectrum intravenous antibiotics (cefuroxime $80.0 \mathrm{mg} / \mathrm{kg}$ /day, metronidazole $20.0 \mathrm{mg} / \mathrm{kg} / \mathrm{day}$, and amikacin $15.0 \mathrm{mg} / \mathrm{kg} / \mathrm{day}$ ), a proton-pump inhibitor (omeprazole $2.0 \mathrm{mg} / \mathrm{kg} / \mathrm{day}$ ), and total parenteral nutrition. Follow-up abdominal X-ray performed after two days (Fig. 2) demonstrated complete resolution of gastric pneumatosis. The gastric fluid culture was positive for Enterococcus faecalis and Bacillus spp., which were sensitive to the antibiotic used. The stool culture detected only non-pathogenic bacteria (Streptococcus spp. and ESBL-negative Enterobacteriaceae). The blood cultures were negative. In the following days, a gradual bowel function recovery was noted, and diarrhoea was not observed. Oral feeding was slowly reintroduced, and the boy was discharged home.

\section{DISCUSSION}

Pneumatosis limited to the wall of the stomach and duodenum is an extremely rare finding $[1,2]$. Moreover, in the paediatric population, pneumatosis is considered rather an uncommon condition and usually is observed in premature babies with necrotising enterocolitis $[3,4]$.

Because there are many diseases connected with this phenomenon, its pathogenesis has been assumed to be multifactorial $[4,5]$. Regarding the stomach, there are two main conditions requiring differentiation: gastric pneumatosis (also known as gastric emphysema) and emphysematous gastritis $[6,7]$.

In gastric pneumatosis, gas enters and accumulates within the wall of the stomach due to the mucosal breach. The aetiology might be idiopathic, but in most cases it is caused by trauma, proximal gastric outlet obstruction, or cardiopulmonary disease. The patients are usually asymptomatic; therefore, searching for the cause is important because it determines the selection of the best clinical approach [5]. Often, the gas can reabsorb spontaneously within a few days only with conservative therapy. In some cases (e.g. gastric outlet obstruction) the surgery treatment is crucial for therapeutic success [1].

Emphysematous gastritis, on the other hand, usually occurs as a result of infection by gas-forming bacteria, corrosive ingestion, or alcohol abuse. In contrast to gastric pneumatosis, patients usually present with acute abdominal pain, shock, fever, nausea, haematemesis, and signs of toxaemia. However, in some conditions, the symptoms may be less pronounced (e.g. diabetes, steroids 
use, renal failure, or broad-spectrum antibiotics coverage). Emphysematous gastritis has a poor prognosis with a high mortality rate (up to $80 \%$ ) $[5,8]$.

There is no approved algorithm allowing us to assess the severity of the patient's illness and indisputably distinguish between the diseases mentioned above. The radiological morphology of gas formations is not useful in the process of differentiation. Initially, it was assumed that in gastric pneumatosis air creates linear patterns outlining the contours of the stomach and in emphysematous gastritis the gas forms a more frothy and bubbly pattern [5]. However, it has been observed that those two conditions can mimic each other in relation both to the clinical symptoms and radiological image, and they are often indistinguishable on plain film X-ray [4].

In our patient, given his medical history of surgical correction of congenital obstruction, surgical consultation and excluding gastric outlet obstruction were vital to determining further treatment. The history of diarrhoea indicating prolonged gastrointestinal infection led to the administration of broad-spectrum intravenous antibiotics and a continuation of temporary bowel rest. As a result, improvement of the patient's general condition and complete resolution of gastric pneumatosis was achieved.

During our research, we came across cases of pneumatosis in neonates, both preterm and term, in relation to conditions such as necrotising enterocolitis, non-invasive ventilation or congenital heart disease $[9,10]$. There are only individual reports of the older infants with gastric pneumatosis, predominantly associated with proximal gastric outlet obstruction $[11,12]$.

\section{CONCLUSIONS}

Though pneumatosis itself should be presumed as a radiological sign, it is important to remember that it can be a manifestation of underlying pathological processes varying from benign to life-threatening. Recognition of the underlying aetiology plays a significant role in further management and estimation of prognostic standpoint. However, it is important to simultaneously take into consideration clinical data, laboratory results, and radiological findings as well as the patient's medical history and coexisting diseases.

\section{DISCLOSURE}

The authors declare no conflict of interest.

\section{REFERENCES}

1. Fernandes AR, Smith WG. Gastric pneumatosis in an eight-monthold girl. Paediatr Child Health 2014; 19: 463-464.

2. Travadi JN, Patole SK, Simmer K. Gastric pneumatosis in neonates: revisited. J Paediatr Child Health 2003; 39: 560-562.
3. Kawano S, Tanaka H, Daimon Y, et al. Gastric pneumatosis associated with duodenal stenosis and malrotation. Pediatr Radiol 2001; 31: 656.

4. Torres US, Fortes CDFM, Salvadori PS, et al. Pneumatosis From Esophagus to Rectum: A Comprehensive Review Focusing on Clinico-Radiological Differentiation Between Benign and Life-Threatening Causes. Semin Ultrasound CT MR 2018; 39: 167-182.

5. Harmse W, Smith V, Stoker A. Intramural gastric air - gastric pneumatosis of emphysematous gastritis. SA J Radiol 2007; 9: 57-58.

6. Agha FP. Gastric Emphysema: An Etiologic Classification. Australas Radiol 1984; 28: 346-352.

7. Case WG, Hall R. Surgical treatment of pneumatosis coli. Ann R Coll Surg Engl 2014; 96: 11-13.

8. Al-Jundi W, Shebl A. Emphysematous gastritis: case report and literature review. Int J Surg 2008; 6: 63-66.

9. Ting YJ, Chan K, Wong SM, et al. Gastric Pneumatosis in a Premature Neonate. AJP Reports 2011; 1: 11-14.

10. Al-Alaiyan S, Fahad Al-Hazzani F. Gastric Pneumatosis in a Premature Infant with Necrotizing Enterocolitis. J Pediatr Neonatal Care 2017; 6: 00254.

11. Cohen HL, Chism PB, Radtke I. Excessive Bright Echoes Sign for Hypertrophic Pyloric Stenosis Suggest the Diagnosis: Gastric Pneumatosis and Portal Venous Gas in Infants Suggest HPS. J Ultrasound Med 2017; 36: 1059-1063.

12. Leonidas JC, Hall RT. Neonatal pneumatosis coli: a mild form of neonatal necrotizing enterocolitis. Arch Dis Child 1976; 51: 395-398. 